\title{
O circuito inferior da economia urbana e a expansão do circuito superior em Natal-RN/ Brasil
}

\author{
Thiago Augusto Nogueira de Queiroz
}

Este trabalho é parte da monografia de conclusão da graduação em Geografia (bacharelado), intitulado “As Feiras Livres de NatalRN: um estudo a partir da teoria dos circuitos da economia urbana".E-mail: thiagoanqueiroz@gmail.com

Recebido em 01/2012. Aceito para publicação em 04/2012.

Versão online publicada em 17/11/2012 (http://seer.ufrgs.br/paraonde)

\begin{abstract}
Resumo - Este trabalho tem como objetivo analisar as conseqüências da expansão dos vetores modernizantes da globalização no contexto do circuito inferior da economia urbana de Natal, capital do estado do Rio Grande do Norte. Como procedimento de pesquisa realizou-se uma revisão teórica e conceitual sobre o assunto, bem como foram realizadas entrevistas com lojistas e camelôs nos bairros comerciais de Cidade Alta e Alecrim. Sabe-se que há uma dependência e uma integração entre os circuitos superior e inferior da economia urbana, pois estes originam-se do mesmo processo que é a modernização tecnológica, contraditória e desigual espacialmente, havendo sempre uma dependência do circuito inferior em relação ao circuito superior. Nesse contexto, observa-se que a instalação dos shoppings centers, hipermercados, supermercados e outros importantes estabelecimentos comerciais no/do espaço de Natal acarretaram mudanças na clientela do circuito inferior, conseqüência principal da disponibilidade de crédito dos agentes do circuito superior, fazendo com que a população de baixa renda consuma, também, no circuito moderno da economia urbana.
\end{abstract}

Palavras-chave: Economia Urbana. Circuito Inferior. Circuito Superior. Natal-RN. Brasil.

\section{Notas introdutórias}

A análise da modernização pode se constituir numa das melhores formas de se entender as relações temporais no espaço (SANTOS, 2004). A abordagem de um fenômeno a partir das modernizações permite datá-lo levando-se em conta a gênese, a evolução e a situação atual. Assim, deve-se entender a periodização da história a partir de modernizações sucessivas. Evita-se, portanto, o erro de colocar lado a lado a teoria de um período e a realidade de outro.

O período é um conjunto coerente de elementos econômicos, sociais, políticos e morais, que constituem um verdadeiro sistema. Cada um desses períodos é representado por uma modernização. A modernização traz diversos impactos sociais, econômicos e políticos no espaço.

As transformações no espaço ocorrem devido às primeiras modernizações, quando o espaço entra no sistema mundial, bem como devido aos impactos sucessivos de outras modernizações, quando novos dados são acrescentados a atual situação geográfica. Nesse contexto, cada espaço possui sua própria evolução e contexto de transformações, resultado de forças externas e de forças pré-existentes no espaço, daí as diferentes situações do subdesenvolvimento, e a singularidade de situa-ção de cada lugar. 0 mundo tem passado por sucessivas e progressivas modernizações, mas, de forma equivocada alguns estudiosos associam modernização com desenvolvimento. Nesse senti-do, vários estudos foram feitos na tentativa de analisar as moderniza-ções do mundo. Diante desse fato, Santos (2004) propõe três períodos de modernização para os países subdesenvolvidos.

O primeiro período corresponde ao fim do século XV até a Revolução Industrial, fruto da modernização comercial, quando se esboça a primeira divisão internacional do trabalho. 0 se-gundo período se inicia em meados do século XVIII e prolonga-se até o fim da Segunda Guerra Mundial, fruto da modernização industrial, acompanhada da modernização dos transportes, dos portos e das ferrovias. $\mathrm{O}$ terceiro período começa em meados do século XX e se estende até o presente, fruto da modernização tecnológica, com uma revolução do consumo e um processo contraditório e desigual de industrialização dos países subdesenvolvidos.

As modernizações atuais são fruto do sistema tecnológico, comandadas pelas firmas multinacionais, monopólios e oligopólios (SANTOS, 2004). A informação e o consumo se difundem nos países subdesenvolvidos, logo, a revolução do consumo que marca este período tem acarretado novas formas de produção e de comércio. Essas moderniza- 
ções criam poucos empregos no mundo subdesenvolvido, fazendo com que um significativo número de pessoas percebam salários muito baixos, vivendo de atividades ocasionais. Cria-se a divisão social entre aqueles que têm acesso permanente aos bens e serviços oferecidos, e aqueles que têm as mesmas necessidades, mas, não têm condições de satisfazêlas. Daí surgem os dois circuitos na economia urbana: o circuito superior, moderno, mono-polístico; e o circuito inferior, não-moderno, pobre.

0 circuito superior "é o resultado direto da modernização tecnológica. Consiste nas atividades criadas em função dos progressos tecnológicos e das pessoas que se beneficiam deles" (SANTOS, 2004, p.38). O circuito inferior "é igualmente um resultado da mesma modernização, mas um resultado indireto, que se dirige aos indivíduos que só se beneficiam parcialmente ou não se beneficiam dos processos técnicos recentes e das atividades a eles ligadas" (SANTOS, 2004, p. 38). Portanto, nos países subdesenvolvidos, a modernização cria formas integradas da organização econômica urbana.

A teoria dos dois circuitos da economia urbana mostra que a cidade não é apenas uma máquina viva. A teoria mostra que os dois circuitos são subsistemas que compõem o sistema urbano dos países subdesenvolvidos. Explica-se sob uma nova ótica a cidade, sua região de influência e a relação com outras cidades, tornando-se um novo paradigma da geografia urbana e da planificação nos países subdesenvolvidos.

0 circuito superior é "constituído pelos bancos, comércios e indústrias de exportação, indústria urbana moderna, serviços modernos, atacadistas e transportadores" (SANTOS, 2004, p. 40). 0 circuito inferior "é constituído essencialmente por formas de fabricação não-'capital intensivo', pelos serviços não-modernos fornecidos 'a varejo' e pelo comércio não-moderno e de pequena dimensão" (SANTOS, 2004, p. 40).

O circuito superior pode ser distinguido em atividades puras, impuras e mistas. As atividades puras são aquelas específicas da cidade e do circuito superior como a indústria moderna, o comércio e os serviços modernos. As atividades impuras são aquelas que o interesse está fora da cidade como as indústrias de exportação, o comércio de exportação, e os bancos. As atividades mistas são aquelas que têm laços com o circuito superior e com o circuito inferior da economia urbana e regional, como os atacadistas e os transportadores.

É necessário refutar o dualismo na/da economia urbana dos países subdesenvolvidos, pois os circuitos têm a mesma origem, o mesmo conjunto de causas e são integrados.
É importante se ater as especificidades dos circuitos da economia urbana para não cair no erro de comparar o que aconteceu com o processo de industrialização das cidades dos países desenvolvidos com o que vem ocorrendo nos países subdesenvolvidos (SANTOS, 2004). Não se pode confundir, também, a economia dos guetos e a economia das favelas com o circuito inferior, pois os guetos são originários de outro período, e as populações dos guetos e das favelas não correspondem a todos os pobres da cidade.

0 fenômeno dos dois circuitos é contemporâneo ao período atual de modernização, não podendo ser encontrado nos países subdesenvolvidos antes da Segunda Guerra Mundial, mesmo que estes tenham se industrializado anteriormente. Hoje, as cidades médias e até as pequenas possuem um comércio integrado ou especializado, caracterizando a interação entre os circuitos.

Nesse contexto, este estudo tem como objetivo analisar as conseqüências, para o circuito inferior da economia urbana, da expansão das atividades de comércio moderno, através da criação dos shoppings centers, hipermercados, supermercados, lojas de departamento e boutiques na cidade de Natal, capital do estado do Rio Grande do Norte (RN). É notório que a instalação de empreendimentos da economia moderna em Natal acarretou mudanças na clientela da economia pobre. Isso ocorre principalmente pela disponibilidade de crédito por parte dos agentes do circuito superior, através de bancos e financeiras, fazendo com que a população de baixa renda consuma, também, no circuito moderno da economia urbana. Sabe-se que há uma integração entre os circuitos superior e inferior da economia urbana, e uma dependência deste para aquele.

Portanto, não serão consideradas as atividades de outros tipos de serviços e/ou indústrias que também compõem a economia urbana. 0 setor estudado corresponde apenas a uma parte do circuito inferior, formada por lojas de pequenas dimensões, de base familiar e de organização nãomoderna que utiliza como tecnologia o trabalho intensivo, além de alguns comerciantes ambulantes

Constituem-se procedimentos de pesquisa nesse trabalho a realização de uma revisão teórica e conceitual sobre o processo de desenvolvimento no mundo subdesenvolvido, especialmente no tocante a teoria dos circuitos da economia urbana, bem como realizaram-se entrevistas com lojistas e camelôs nos bairros comerciais de Cidade Alta e Alecrim, principais bairros comerciais da cidade. Nota-se aí uma nítida presença do circuito inferior 
ligado ao circuito moderno, que Santos (2004) denominou de circuito inferior central, este

ligado à população do centro, mas caracteriza-se, além disso, pelas relações privilegiadas com as outras atividades centrais, entre as quais as atividades do setor moderno; sua clientela, aliás, ocasionalmente pode ser a mesma do circuito superior (SANTOS, 2004, p. 350).

$\mathrm{Na}$ pesquisa empírica buscou-se obter informações sobre o tempo de existência e funcionamento do estabelecimento, clientela, isto é, público-alvo, principal classe social, principais mudanças ocorridas com a expansão do comércio moderno na cidade em termos de produtos comercializados, "novos" tipos de clientes, e dinâmica comercial do bairro. As entrevistas foram realizadas com 20 comerciantes representantes de lojas pertencentes ao circuito inferior da economia dos bairros do Alecrim e de Cidade Alta, tradicionais áreas do comércio de Natal.

\section{A pobreza urbana e o circuito inferior}

As discussões sobre a pobreza estão sendo feitas, na maioria das vezes, ligadas a teoria da marginalidade (SANTOS, 2009). A antiga e ativa discussão desse problema não resultou em nenhuma teoria real. Muitas vezes foi utilizada a antiga idéia de exército industrial de reserva. A pobreza foi tema de muitos escritos, mas, que não serviram para encontrar um tratamento eficiente para este mal. A abordagem sobre a pobreza através da teoria da marginalidade não é satisfatória.

Para Santos (2009) os estudos sobre pobreza deveriam ser feitos a partir do processo de modernização, pois, facilita o entendimento do problema em todos os níveis. 0 progresso técnico muda a composição técnica do capital e reduz a demanda de mão-de-obra, principalmente, nos setores mais afetados pela modernização. A economia urbana deve ser estudada como um sistema único, formado por dois subsistemas, o circuito superior e o circuito inferior.

Segundo Santos (2009) as repercussões do atual período histórico sobre os países subdesenvolvidos são múltiplas e profundas. A indústria, no progresso tecnológico atual cria um número limitado de empregos e usa capital intensivo. A sociedade urbana é dividia entre aqueles que têm acesso às mercadorias e serviços que necessitam, e entre aqueles que têm a mesma necessidade, mas não tem como satisfazê-las devido a insuficiência de dinheiro. Os pobres não têm acesso a um consumo variado de mercadorias modernas, pois são obriga- dos a consumirem esporadicamente produtos manufaturados, normalmente de qualidade inferior, produzidos por pequenas empresas ou artesões.

É importante frisar que o circuito inferior não pode ser analisado como tradicional ou como informal apenas. Muitos fornecimentos ao circuito inferior são originados no circuito moderno, não podendo ser chamado de tradicional. Este possui suas próprias leis operacionais e de evolução, sua própria organização, não podendo ser chamado de informal.

0 circuito inferior "é formado essencialmente de diferentes tipos de pequeno comércio, e da produção de bens manufaturados de capital não intensivo, constituída em grande parte de artesanato e também de toda uma gama de serviços não modernos" (SANTOS, 2009, p. 48).

0 circuito superior usa como tecnologia o capital intensivo, enquanto o circuito inferior tem como principal tecnologia a mão-de-obra. 0 circuito superior opera com crédito bancário, o circuito inferior tem um crédito pessoal, usurário. As atividades do circuito superior envolvem um grande volume de mercadorias e de capital, enquanto as do circuito inferior lidam com pequenas quantidades, um trabalho intensivo e uma organização burocrática.

De acordo com Santos (2009) devemos evitar o dualismo na análise dos circuitos da economia urbana, pois os dualistas, quando estudam os países subdesenvolvidos, crêem na oposição entre um setor desenvolvido, coerente de ações eficientes e racionais, e um setor não desenvolvido, inarticulado, com ações arcaicas, irracionais e ineficientes. Mas não existe apenas uma racionalidade econômica, existem diversas racionalidades, portanto, não sendo adequado o termo setor informal para designar/definir o circuito inferior.

Muitos trabalhos mostram que o chamado setor informal, possui uma profunda racionalidade da economia da pobreza urbana no Terceiro Mundo, haja vista que essas atividades também são eficientes. Para denominar uma ação humana de irracional é preciso provar que essa ação não tem objetivo ou não tem comportamento firme e normas efetivas. 0 circuito inferior da economia urbana é

um mecanismo permanente de integração que oferece um número máximo de oportunidades de emprego com um volume mínimo de capital. Esse circuito corresponde exatamente às condições gerais de emprego e disponibilidade de dinheiro, assim como às necessidades de consumo de uma importante fração da 
população. Seu funcionamento é dirigido por leis, isto é, por uma constância de comportamento de vida a causas que por sua vez também se repetem (SANTOS, 2009, p. 67).

A noção de informalidade ou irracionalidade de um dos dois setores significaria que essa sociedade não opera de forma global. 0 circuito inferior funciona através de "diferentes fatores ligados entre si por uma lógica que é ao mesmo tempo econômica, social e política". A definição de setor informal e de setor formal é deficiente porque inverte a realidade social, baseando-se em um único critério, o da produtividade do trabalho, aspectos quantitativos. Utilizando-se esses critérios pode-se pensar que o problema se resolveria aumentando a produtividade do circuito inferior, ou seja, tornando-o mais capitalista.

Uma melhoria no mecanismo de trocas terá pouco significado se o fluxo de mais-valia continuar empobrecendo uns e enriquecendo outros (SANTOS, 2009). A eliminação da situação de dependência do circuito inferior em relação ao superior só será possível com uma mudança estrutural. 0 circuito inferior é um sistema. E mesmo que este circuito seja dinâmico, seu dinamismo é dependente. A análise em torno do planejamento deve levar em conta o dinamismo de uma economia dependente.

As atividades modernas podem até gerar a expansão do assalariado, mas, com a efetiva diminuição do número de trabalhadores em relação ao volume e valor da produção. Os preços no circuito superior são fixos, manipulados, visando lucros a longo prazo, por outro lado no circuito inferior o preço não é fixo, as variações são acentuadas, e o prazo do lucro é curto. No circuito superior a idéia do lucro está ligada a acumulação de capital, e no inferior está ligada a satisfação da sobrevivência da família. A relação entre o agente e a clientela é pessoal e direta no circuito inferior, mas impessoal, centralizada e hierárquica no circuito superior. Apesar do lucro elevado no volume, o rendimento por unidade é baixo no circuito superior, mas no circuito inferior ocorre o oposto.

A atividade no circuito superior baseia-se na publicidade, na modificação de gostos, e alteração no perfil da demanda, no circuito inferior a publicidade é desnecessária e inviável. 0 circuito superior tem custos fixos altos, no circuito inferior quase não há custos fixos. No circuito superior não ocorre o aproveitamento de bens de consumo duráveis, ao contrário do circuito inferior que reutiliza algumas mercadorias. 0 circuito superior apóia-se na ajuda governamental, e o circuito inferior não conta com esse apoio, e muitas vezes, os agentes são perseguidos pelo Estado, a exemplo dos comerciantes ambulantes.

0 Estado deveria ser considerado um elemento do circuito superior. Este depende da viabilidade de capital social novo (overhead) suprido pelo Estado, enquanto no circuito inferior isso não é necessário para a criação de atividades. 0 circuito superior emprega um significativo número de estrangeiros variando com a industrialização e a modernização do país, no circuito inferior os empregos são ocupados por nacionais e ocasionalmente por estrangeiros. 0 circuito inferior é integrado localmente, já o circuito superior de uma cidade é integrado com cidades de nível mais alto, ou com as de outra parte do país, ou as de outro país.

A maioria dos consumidores do circuito inferior são os pobres, ou seja, aqueles que não têm acesso aos bens de consumo considerados como o mínimo indispensável. Os consumidores do circuito superior são via de regra os indivíduos mais abastados, os quais geralmente mantêm o controle da economia urbana e regional e até nacional, ou seja, são os proprietários das grandes firmas da economia moderna e agentes de finança.

As classes médias são formadas por assalariados que se situam acima do nível de subsistência, além dos proprietários e empresários cujos ganhos são insuficientes para que passem para as classes superiores. A existência de três classes sociais no mundo subdesenvolvido não significa a existência de três circuitos da economia urbana. Alguns consumos da classe média (casa, automóvel, lazer) são alinhados aos consumos da classe superior, e outros consumos (como os produtos alimentícios) são realizados no circuito inferior, no entanto não existe um circuito intermediário.

Os dois circuitos possuem contradições em suas características. Mas cada circuito tem sua própria variável de tecnologia, organização, importância das atividades, relações de trabalho, e número de empregos. Os dois circuitos se complementam, apesar da dominação do circuito superior. 0 estudo da cidade enquanto totalidade não é possível sem o exame da dialética entre os dois circuitos.

\section{O circuito inferior e a expansão do circuito supe- rior da economia urbana natalense}

Nas últimas décadas a instalação de empreendimentos do circuito superior em Natal acarretou mudanças na clientela da economia pobre. Isso ocorre principalmente pela disponibilidade de crédito das lojas do circuito superior, através de 


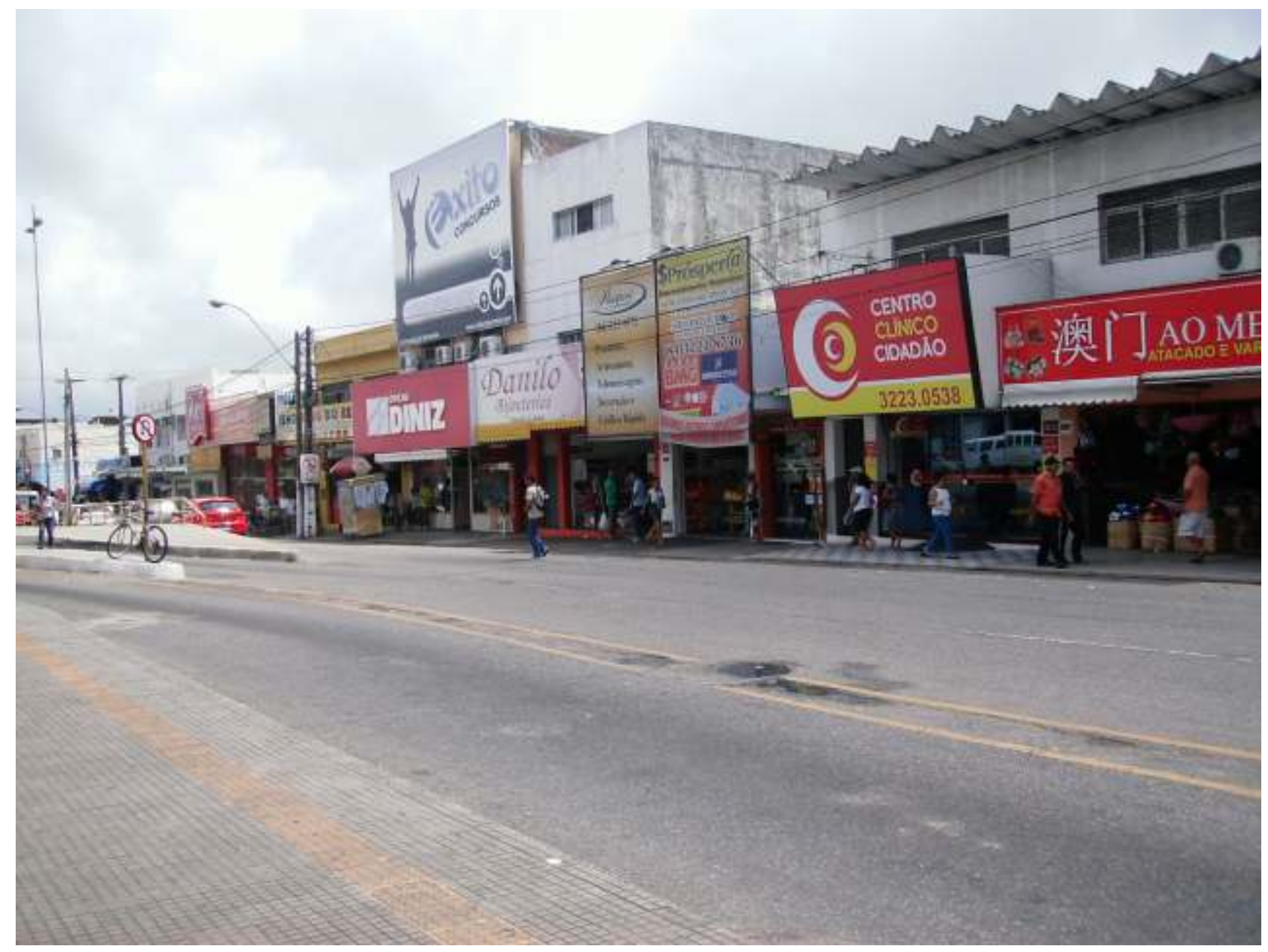

Figura 1. Avenida Presidente Bandeira no Bairro Alecrim. Foto: Thiago Augusto Nogueira de Queiroz, março 2011.

bancos e financeiras, fazendo com que a população de baixa renda consuma, também, no circuito moderno da economia urbana. As próprias empresas do circuito moderno passam a localizarem-se em áreas onde predominava o circuito nãomoderno, ocorrendo o que Silveira (2009) denominou de formação de áreas de diversidade (Figura 1).

De forma direta e indireta o banco é o agente hegemônico do circuito superior, seja através da concessão de créditos em seu próprio nome ou através de representantes (SANTOS, 2004). Estes se disseminam a medida que há uma difusão da monetarização dos países. Os bancos financiam atividades comerciais que proporcionam uma maior rotatividade do capital em um prazo mais curto, com menores riscos e maiores lucros. Os bancos também financiam as atividades agrícolas, principalmente, as atividades voltadas para a exportação e vários outros tipos de negócios. Ao mesmo tempo em que o banco canaliza capitais externos para a região ou para a cidade, modernizando a economia local, o fluxo de fundos vão para os países sedes desses bancos, os países desenvolvidos.
Diante disso, Silveira (2009) mostra em vários de seus estudos a importância das firmas financeiras no circuito superior. A cidade de São Paulo é sede de vários bancos do Brasil, e sub-sedes de bancos internacionais, de onde controla todo um sistema bancário nacional. A autora mostra a interferência do dinheiro global na cidade, e a importância dos créditos em várias empresas. 0 crediário disponível em lojas de confecções, por exemplo, é uma forma do circuito superior também atrair uma clientela pobre, enfraquecendo a procura desses consumidores no circuito inferior.

Observa-se que no bairro da Cidade Alta em Natal ocorre a transição, isto é, a mudança de um comércio burguês para um comércio popular, ou seja, com a chegada de grandes empreendimentos do circuito superior em outras áreas da cidade, o circuito inferior passa a crescer neste tradicional bairro comercial da cidade, ocorrendo o processo de formação de áreas de diversidade, como exemplo tem-se a formação de um "Shopping Popular", um camelódromo na Av. Ulisses Caldas (Figura 2), entre outros eventos que marcam tal processo na economia urbana natalense. 


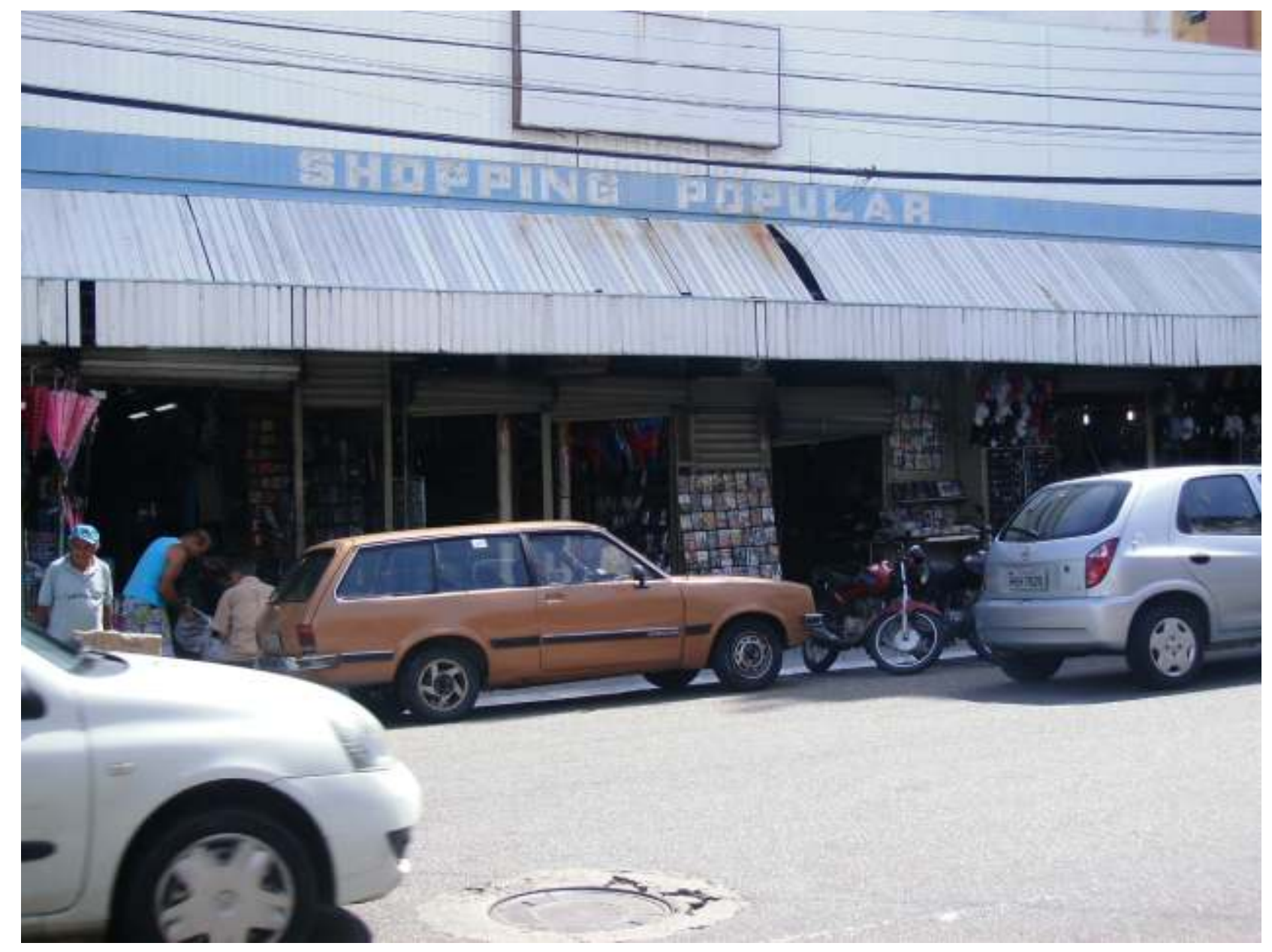

Figura 2. Shopping Popular no Bairro Cidade Alta. Foto: Thiago Augusto Nogueira de Queiroz, março 2011.

A instalação de shopping centers, hipermercados, lojas de departamentos e outros tipos de estabelecimentos comerciais modernos na última década em Natal provocaram mudanças no comércio do bairro de Cidade Alta, a exemplo da diminuição do número de clientes. Os consumidores que continuam a consumir nessas lojas, são consumido-res antigos que possuem uma certa identidade com o empreendimento, os demais trocaram a tumul-tuada situação do bairro pelo conforto dos shop-pings centers.

Vale frisar que os empreendimentos modernos têm intencionalmente uma diversidade de serviços e comércios, oferecendo conforto e como-didade, bem como sensação de segurança e bem-estar, tudo isso concentrado em um só lugar. Esses elementos modernos da economia possuem como principal fator de atração de consumidores a acessibilidade, localizando-se nas principais vias da cidade e em rotas de transportes coletivos urbanos, localizadas normalmente em áreas onde reside uma população de alta renda.

Apesar da forte concorrência exercida pelo circuito moderno, os empreendimentos do circuito inferior da Cidade Alta não modificaram os produtos comercializados. Mas, muitos dos comerciantes temem a falência do empreendimento, devido a diminuição da procura pelos produtos vendidos. Há, portanto uma certa lentidão no ritmo de vendas comparando-se a situação atual com a de 10 anos atrás. Até mesmo as vendas e o movimento de consumidores em datas festivas como o período natalino, dia das mães, dia dos namorados, dia dos pais e dia das crianças tem diminuído.

A situação na área comercial do Alecrim é a mesma. O comércio do Alecrim caracteriza-se sobretudo pela clientela oriunda, principalmente, das áreas pobres da cidade. Essa população procura consumir produtos mais baratos e com certa qualidade, e encontra essas características nos produtos vendidos nessa área comercial da cidade.

Com a expansão do circuito moderno da conomia urbana houve uma perda significativa de clientes devido a forte concorrência, pois nos shoppings centers tem "lojas onde o pobre pode comprar". O raciocínio do lojista mostra que o circuito 
e superior absorve os consumidores que eram anteriormente do circuito pobre, isso se deve, principalmente, a disponibilidade de crédito no circuito superior e a penetração do circuito superior em áreas onde anteriormente predominava o circuito não-moderno. Houve a criação de shopping Center até em áreas de comércio popular como no Alecrim (Figura 3).

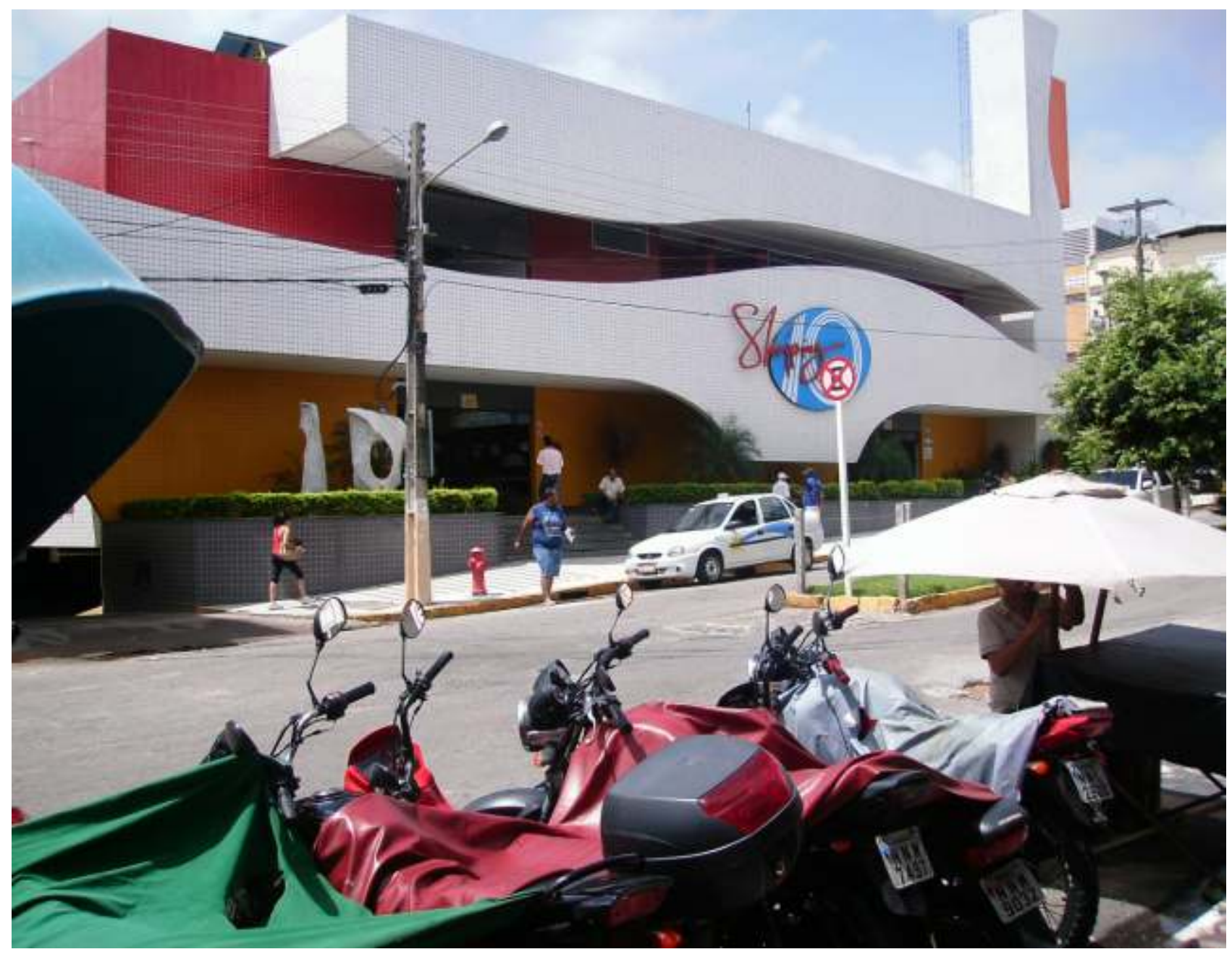

Figura 3. Shopping 10 no Bairro Alecrim. Foto: Thiago Augusto Nogueira de Queiroz, março 2011.

Mas, como alternativa para enfrentar essa forte concorrência, os comerciantes do circuito inferior do Alecrim passaram a vender produtos mais baratos, oferecendo promoções frequentemente. Observou-se que muitos lojistas foram a falência nos últimos anos, sem conseguir concorrer com os monopólios modernos. Na tentativa de "formalizar" o circuito inferior o poder público também atuou na formação de camelódromos como o do Alecrim (Figura 4).

Apesar das falências de algumas lojas, e da forte concorrência do circuito superior, o circuito inferior continua a crescer na capital potiguar, através, por exemplo, das feiras livres (Figura 5). 0 circuito inferior é fruto da pobreza estrutural e uma forma de resistência dos pobres em um momento de oligopolização da economia urbana, o alargamento do circuito superior. Este compor-tamento dos pobres faz parte do existencialismo territorial que é "la forma de supervivencia de la mayor parte de la población brasileña: pragma-tismo más emoción en la búsqueda de soluciones que son vistas como irracionales, como formas de atraso, como economía tradicional" (SILVEIRA, 2004, p. 20).

0 circuito inferior é resultado do acontecer solidário. Para Silveira (2007, p. 18), o acontecer solidário ocorre quando "a simultaneidade e interrelação abriga, como nunca antes, uma oposição". Ou seja, o circuito inferior tem sua origem indiretamente ligada à modernização tecnológica, apresentando uma relação de depen-dência e ao mesmo tempo de contradição com o circuito superior, que é um resultado direto do processo modernizante. 


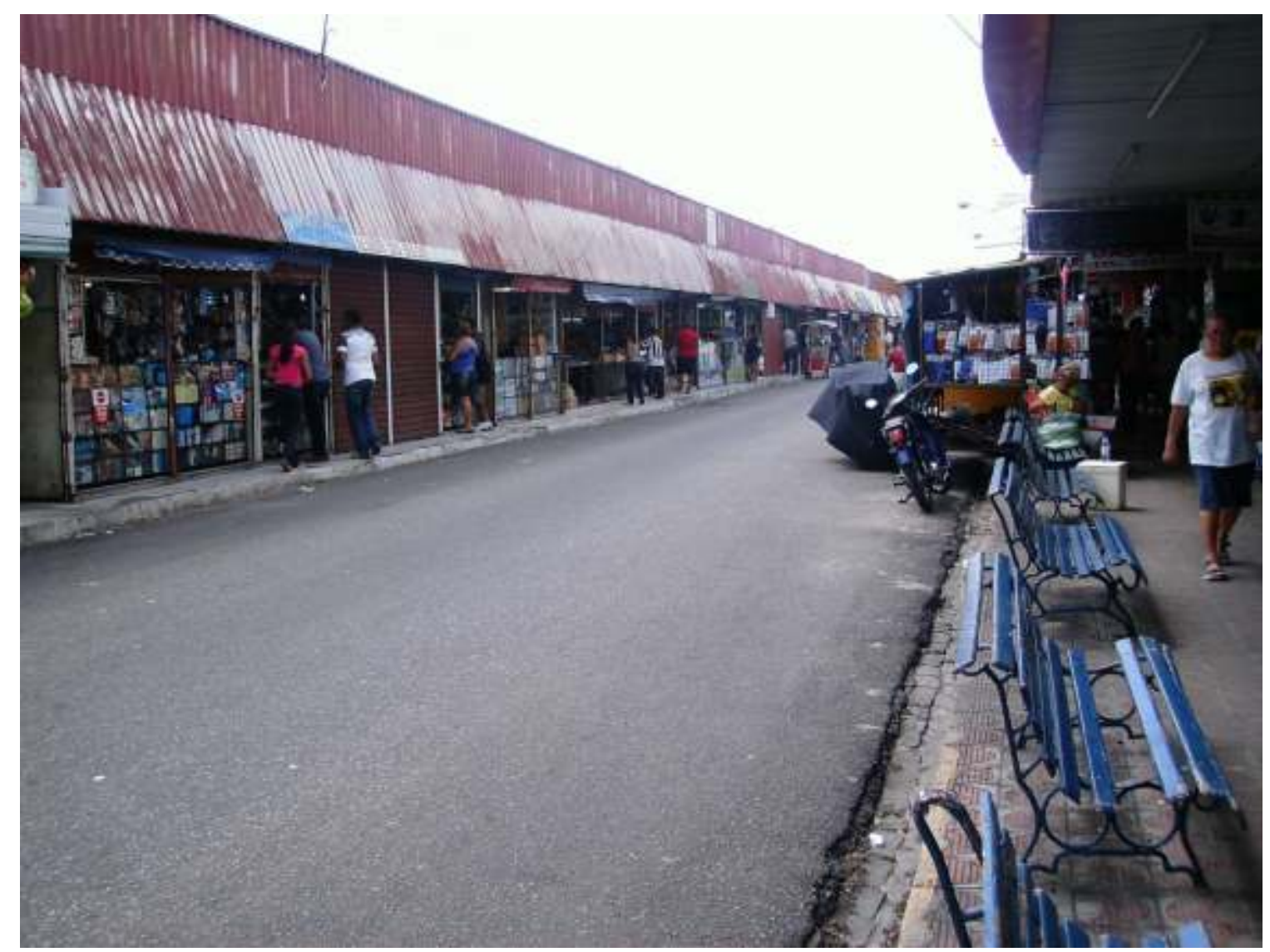

Figura 4. Camelódromo do Alecrim.Foto: Thiago Augusto Nogueira de Queiroz, março 2011.

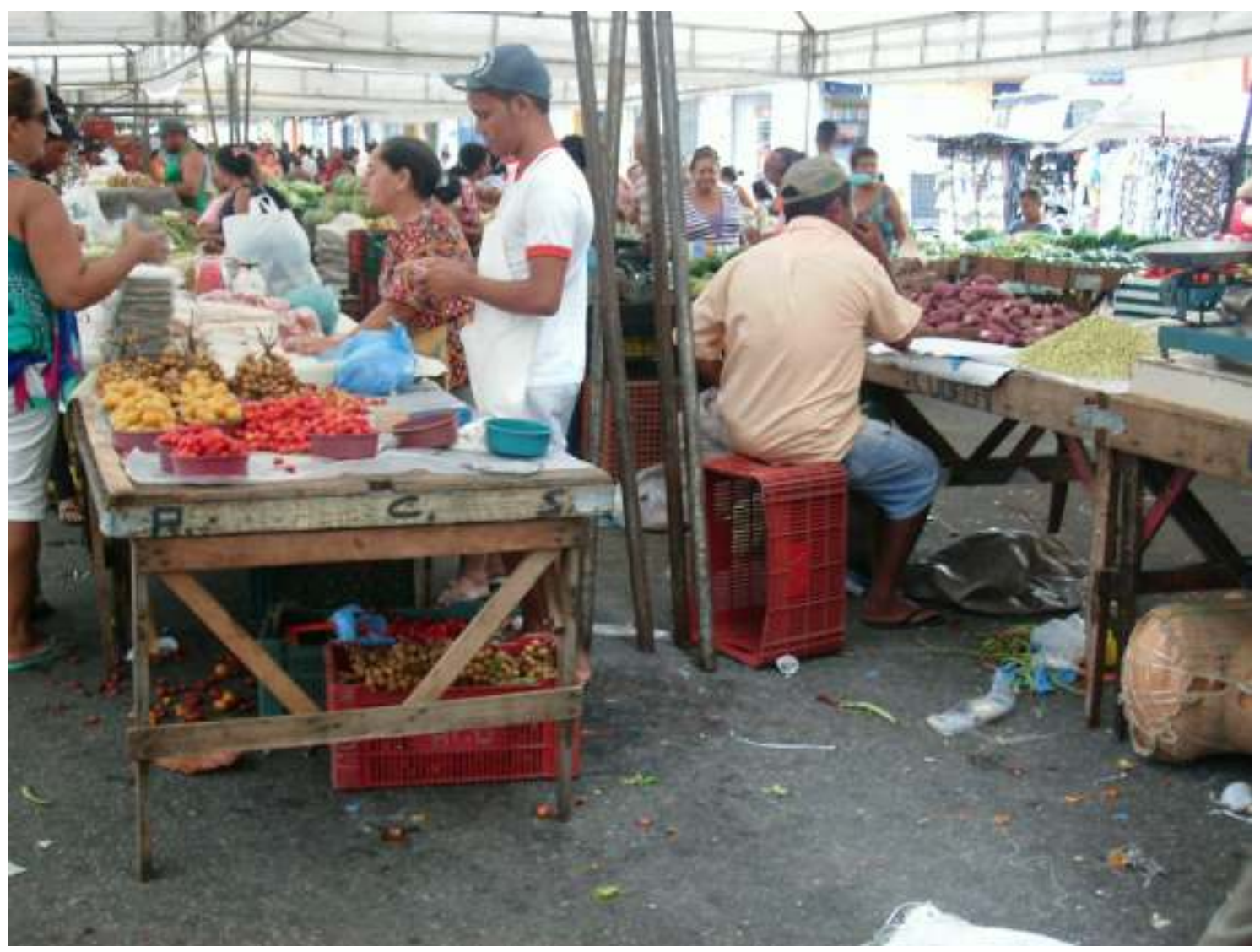

Figura 5. Feira livre do bairro do Alecrim, a mais antiga e importante feira de Natal-RN. Foto: Thiago Augusto Nogueira de Queiroz, maio 2011. 
Para entender os circuitos da economia urbana deve-se analisar a economia política da urbanização e a economia política da cidade em conjunto (SILVEIRA, 2010, p. 1). A economia política da urbanização é "a economia política do território, revelando a repartição dos instrumen-tos de trabalho, do capital, do emprego e dos homens numa formação socioespacial", isto é, a cidade como meio construído. Entender a economia política da cidade significa entender "como o meio construído urbano se organiza face a produção e como os agentes da vida urbana encontram seu lugar nesse meio construído e na divisão do trabalho", isto é, a cidade como mercado.

A cidade é, neste sentido,

o 'prático-inerte' por excelência, pois agrega no seu seio um leque de próteses e semoventes de idades diversas e uma pluralidade de práticas, idéias, normas, cosmovisões e formas de fazer que não se explicam apenas pelo presente nem apenas pela divisão territorial do trabalho hegemônico (SILVEIRA, 2010, p. 9).

Portanto, deve-se entender a cidade como uma superposição de divisões do trabalho, a cidade como meio construído e, a cidade como um mercado. Esse mercado é formado por diversos circuitos de produção, distribuição e consumo. Deve-se, portanto, analisar a cidade como a relação dialética e indissociável entre o circuito superior e o circuito inferior, para poder compreender essa totalidade una e fragmentada.

\section{Considerações finais}

Depreende-se que os dois circuitos da economia urbana dos países subdesenvolvidos é resultado do atual período de modernização, o qual convencionou-se chamar de período técnicocientífico-informacional Trata-se de uma indissociabilidade entre o circuito superior, e o circuito inferior no contexto da modernização tecnológica. Como os empregos gerados pela economia moderna não são suficientes para abarcar uma crescente população urbana, uma grande parte dos citadinos vêem como única forma de sobrevivência as atividades existentes no circuito inferior. Assim, geramse nas cidades diversas divisões territoriais do trabalho que estão superpostas, formando uma totalidade.

Essa interpenetração e essa invasão existente entre os dois circuitos são facilmente observadas nos bairros de Cidade Alta e do Alecrim na cidade de Natal-RN. Nesses bairros há um grande adensamento e contraste entre os dois circuitos, formando-se também áreas de diversi-dade da cidade. Como resultado da pesquisa observa-se que devido a uma maior capilaridade do capital financeiro e também devido a uma forte penetração do circuito superior no espaço construído urbano da cidade de Natal, não obstante a forte presença do circuito inferior nos bairros de Cidade Alta e Alecrim houve uma diminuição da clientela do circuito não-moderno, levando alguns comerciantes a falência. Mas, os outros comer-ciantes desse circuito que resistiram a esse processo procuraram novas alternativas, como freqüentes promoções, para reativar o comércio.

Pensar na formação de cooperativas ou associações de comerciantes do circuito inferior, buscando uma maior organização dos mesmos, torna-se uma importante alternativa para o fortalecimento e a sobrevivência desses agentes econômicos que são desprovidos ou são obsoletos em capital, tecnologia e organização adminis-trativa.

\section{Referências}

SANTOS, Milton. 0 espaço dividido. 2.ed. São Paulo: EDUSP, 2004.

SANTOS, Milton. Pobreza urbana. 3.ed. São Paulo: Edusp, 2009.

SILVEIRA, Maria Laura. Globalización y circuitos de la economía urbana en ciudades brasileñas. Cadernos del Cendes, v. 21, n. 57, p. 3-22, set. 2004.

SILVEIRA, Maria Laura. Crises e paradoxos da cidade contemporânea: os circuitos da economia urbana. Anais do X SIMPURB, Florianópolis, out. 2007.

SILVEIRA, Maria Laura. Finanças, consumo e circuitos da economia urbana na cidade de São Paulo. Caderno CRH, Salvador, v. 22, n. 55, p 65-76, jan./abr. 2009.

SILVEIRA, Maria Laura. Da pobreza estrutural à resistência: pensando os circuitos da economia urbana. Anais do XVI ENG, Porto Alegre, jul. 2010. 


\title{
El bajo circuito de la economía urbana y el crescimento del urbana y el crescimento del circuito superior en Natal-RN/Brasil
}

Resumen - Este trabajo tiene como objetivo analizar las consecuencias de la expansión de los vectores de la globalización en el contexto del circuito inferior de la economía urbana de Natal, capital de Rio Grande do Norte, Brasil. Como los procedimientos de investigación llevado a cabo una revisión conceptual y teórica sobre el tema, así como entrevistas con los vendedores en los distritos comerciales de la Cidade Alta, y Alecrim. Se sabe que hay una dependencia y la integración entre los circuitos superior e inferior de la economía urbana, ya que estos se originan en el mismo proceso que es la modernización tecnológica, contradictoria y desigual en el espacio, siempre hay una dependencia en el circuito inferior en relación con el circuito superior. En este contexto, se observa que la instalación de centros comerciales, hipermercados, supermercados y otras tiendas en lo espacio de Natal dirigido a los cambios en la clientela del circuito inferior, debido principalmente a la disponibilidad de crédito del circuito superior, las personas de bajos ingresos consumen, también, en el moderno circuito de la economía urbana.

Palabras clave: Economía Urbana. Circuito Superior. Circuito Inferior. Natal-RN. Brasil.

\section{The under circuit of urban economy and the governing of the upper circuit in Natal- RN/Brazil}

\begin{abstract}
This study aims to examine what the consequences for the lower circuit of the economy in Natal, Brazil, with the expansion of upper circuit's elements. The methods used included interviews with ambulant and vendors in the commercial districts of Cidade Alta and Alecrim. There is a dependency and integration between the upper and lower circuits of urban economy, both are originated from the same process that is the technological modernization, with a dependence on the lower circuit for the upper circuit. In this context, it was observed that the installation of shopping centers, hypermarkets, and supermarkets in Natal led to changes in the clientele of the lower circuit. This occurs mainly by the availability of credit from the stores of the upper circuit, so, the low income population consumes in the upper circuit.
\end{abstract}

Keywords: Urban Economy. Lower Circuit. Upper Circuit. Natal-RN. Brazil. 